\title{
Insecticide-induced hormesis and arthropod pest management
}

\author{
Raul Narciso C Guedes ${ }^{\mathrm{a} *}$ and G Christopher Cutler ${ }^{\mathrm{b}}$
}

\begin{abstract}
Ecological backlashes such as insecticide resistance, resurgence and secondary pest outbreaks are frequent problems associated with insecticide use against arthropod pest species. The last two have been particularly important in sparking interest in the phenomenon of insecticide-induced hormesis within entomology and acarology. Hormesis describes a biphasic dose-response relationship that is characterized by a reversal of response between low and high doses of a stressor (e.g. insecticides). Although the concept of insecticide-induced hormesis often does not receive sufficient attention, or has been subject to semantic confusion, it has been reported in many arthropod pest species and natural enemies, and has been linked to pest outbreaks and potential problems with insecticide resistance. The study of hormesis remains largely neglected in entomology and acarology. Here, we examined the concept of insecticide-induced hormesis in arthropods, its functional basis and potential fitness consequences, and its importance in arthropod pest management and other areas.
\end{abstract}

(C) 2013 Society of Chemical Industry

Keywords: biphasic concentration-response; hormoligosis; insecticidal stress; insecticide ecotoxicology; pesticide-mediated homeostatic regulation; sublethal effects

\section{HORMESIS: ANCIENT ADAGES, OLD LAWS AND CURRENT THEORY}

Friedrich Nietzsche in his Twilight of the Idols (1888) expressed the maxim that what does not destroy you, makes you stronger. Although not everything that does not kill will make you stronger, Nietzsche's idea is well known in human society and emulates the concept of hormesis, which describes a dose-response phenomenon characterized by a reversal of the response between low and high doses of a stressor, such as an insecticide.

The concept of hormesis may have been developed from the dose-response relationship illustrated by the ancient Greek and Latin adages 'nothing too much' and 'the virtue is in the middle', respectively. ${ }^{1,2}$ In the 16 th century, the monophasic dose-response concept was applied to the discipline of toxicology by Paracelsus, who recognized that the dose makes the poison, ${ }^{3}$ meaning that toxic substances are nonpoisonous at low enough doses, and what are generally innocuous substances can be toxic at high enough doses. The sigmoid or linear (on a loglogit or a log-probit scale), or also monophasic dose-response relationship was initially challenged in the late 19th century by Hugo Schulz, who demonstrated stimulation by substances at low (sublethal) concentrations that are toxic at high concentrations. ${ }^{4}$ This (nonlinear) biphasic relationship described by Schulz was referred as the Arndt-Schulz law. This law was co-opted by the homeopathic community as its scientific principle, which, in part, led to its marginalization. It was later re-established by Ferdinand Hueppe and has become known as Hueppe's rule. ${ }^{2,5-7}$

The term 'hormesis' has its beginning in the early 1940s when Chester M Southam and John Ehrlich observed a biphasic dose-response to red cedar extracts in different fungal strains, and they referred to the phenomenon as 'hormesis', from the Greek 'to excite'. 8 More recently, Edward J Calabrese and his group recognized the general nature of the phenomenon in a succession of meta-analyses. ${ }^{9-13}$ They suggested that the hormetic dose-response model is more common in toxicology than the threshold model (Fig. 1), which is widely viewed as the most dominant model in toxicology. ${ }^{9-13}$ The common definition of hormesis as the stimulatory effect associated with low (sublethal) doses of compounds that are toxic at higher doses has been refined to avoid referring to the response as 'beneficial', which may not always be the case. Hormesis, therefore, can be defined as a dose-response relationship characterized by a reversal in response between low and high doses of a stressor (e.g. an insecticide), thus characterizing a biphasic relationship. ${ }^{2,14}$ Doses that cause hormetic responses are limited in range and typically below the No Observable Effects Concentration (Fig. 1), although this is not always the case for arthropods in their response to pesticides. ${ }^{15}$

\section{CONCEPTUAL CONUNDRUM IN ENTOMOLOGY AND ACAROLOGY}

The concept of hormesis is now widely recognized and accepted as a general stress response phenomenon. ${ }^{2,13-16}$ Semantically, however, insecticide-induced hormesis remains subject to

\footnotetext{
* Correspondence to: Raul Narciso C. Guedes, Departamento de Entomologia, Universidade Federal de Viçosa, Viçosa, MG 36570-000, Brazil. E-mail:guedes@ufv.br

a Departamento de Entomologia, Universidade Federal de Viçosa, Viçosa, (MG), Brazil

b Department of Environmental Sciences, Agricultural Campus, Dalhousie University, Truro, (NS), Canada
} 


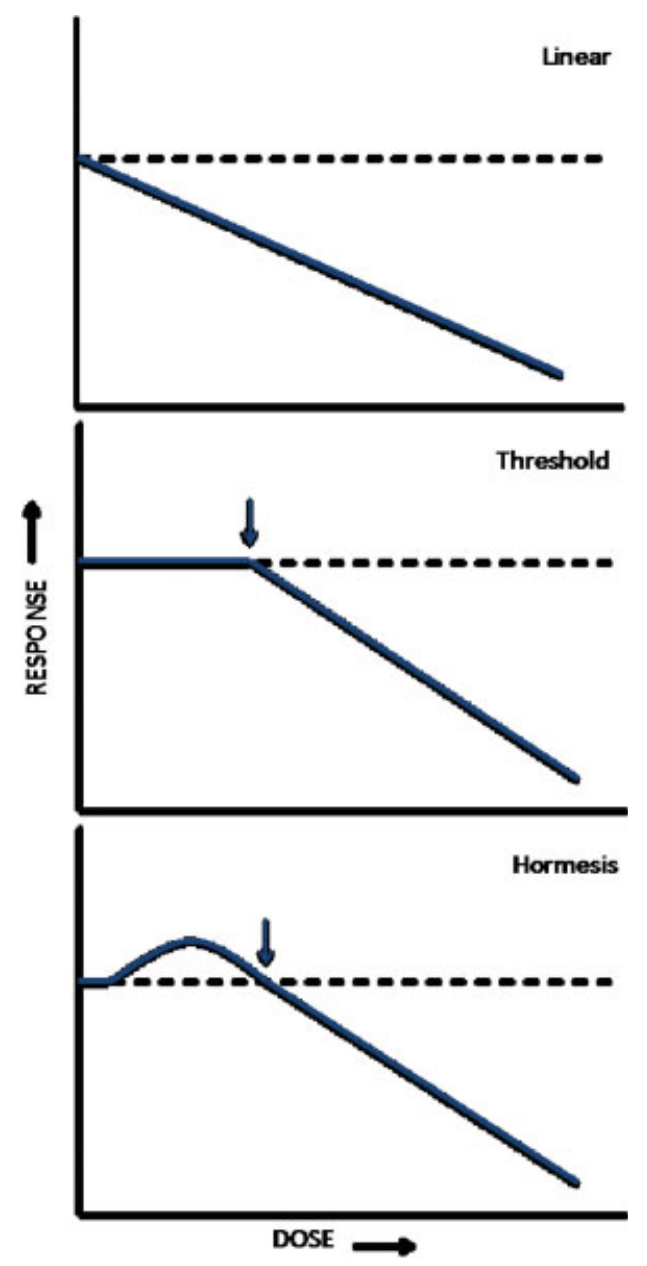

Figure 1. Depiction of the linear, threshold and hormesis dose-response models (solid line) generally used in toxicology (a log-logit or log-probit scale was assumed allowing for a linear relationship). Arrows indicate the No Observable Effects Concentration. The black dashed line indicates the (control) expected response without insecticide exposure.

confusion in entomology and acarology. In these fields, two additional terms, 'insecticide hormoligosis' and 'pesticide-mediated homeostatic modulation', have been used synonymously, analogously or complementary to the concept of hormesis. The historical precedence of the term 'hormesis' and the generality of this concept make this semantic confusion unnecessary and difficult to justify. In addition, there are misunderstandings (or misconceptions) about the original definitions of hormoligosis and pesticide-mediated homeostatic modulation.

\subsection{Insecticide hormoligosis}

The term 'hormoligosis', or more precisely 'insecticide hormoligosis', was coined by Thomas D Luckey in his influential 1968 paper. Luckey developed the term from the Greek hormo (= to excite) and oligo (= small quantities) and defined it as a phenomenon in which '... subharmful quantities of many stress agents may be helpful when presented to organisms in suboptimal environments $\ldots{ }^{\prime 17}$ This original definition emphasizes situations in which stimulation under sublethal exposure of a given compound will occur when the organism is already under stress (i.e. due to suboptimal conditions or a second stress agent). This concept is distinct from that of hormesis, although the later encompasses the former; therefore, insecticide hormoligosis is basically a special case of hormesis in which a biphasic dose-response for an insecticidal compound is observed when the organism is already under stress due to another environmental factor or agent.

The distinction between hormesis and hormoligosis has been previously recognized. ${ }^{15,18,19}$ Nonetheless, most entomological and acarological studies neglect the distinction between the terms, particularly regarding the suboptimal environment in which insecticide hormoligosis is referred to take place. Indeed, hormesis and hormoligosis have been equivocally redefined and are treated synonymously in the insecticide and acaricide literature, ${ }^{20,21}$ likely contributing to the semantic confusion. However, a shift favoring the proper recognition of the hormesis phenomenon within insecticide toxicology seems to be taking place, ${ }^{18,19,22}$ which should reduce the misuse of the term 'hormoligosis' (Fig. 2). The term insecticide hormoligosis, if used, should be restricted to cases of insecticideinduced hormesis where the biphasic dose-response takes place when the organism in already under stress due to another environmental factor.

\subsection{Pesticide-mediated homeostatic modulation}

The concepts of hormesis and insecticide hormoligosis as they related to arthropods and insecticides in certain situations were recently questioned by Cohen, ${ }^{18}$ and have received some support (e.g. Yu et al). ${ }^{23}$ Cohen readily recognizes the conceptual distinction between hormesis and hormoligosis, and the general misuse of the latter when referring to the former in insecticide studies with insects and mites. The concept of hormesis was, however, challenged by Cohen in favor of 'pesticide-mediated homeostatic modulation' in arthropods in two circumstances: (1) hormesis is not applicable to situations in which stimulatory effects are observed in a nontarget pest species not controlled by the pesticide under consideration; and (2) one can only quantitatively measure lethal doses of a given pesticide in target pests. ${ }^{18}$ However, the hormesis concept is not species- or target-driven and the homeostatic modulation notion is management-based (i.e. determined by the field use of registered recommendations) rather than the toxicological dose-response. ${ }^{15}$ Furthermore, the suggestion that the quantification of dose-response relationships and determination of lethal doses as toxicological endpoints are only possible in target species is incorrect.

\section{FUNCTIONAL BASIS AND POTENTIAL FITNESS CONSEQUENCES}

The mechanisms underlying insecticide-induced hormesis in arthropods remain largely unknown, despite a few recent advances. ${ }^{14,23,24}$ Recognition of the mechanisms underlying hormesis is crucial to understand the process and its relevance and consequences. ${ }^{14,25,26}$ In a general sense, different hormetic agents, chemicals, radiation, temperature, etc. likely change gene expression in components of physiological response pathways, including hormones, heat shock proteins and antioxidant enzymes, ${ }^{23,27-29}$ ultimately affecting fitness-related traits. ${ }^{14,16,30,31}$ Two main overall alternative hypotheses currently prevail in providing a mechanistic explanation for hormesis: the growth hormesis theory of Stebbing (also referred to as growth control, the Maia hypothesis and 'overcompensation' theory), ${ }^{30,32-34}$ and the principle of physiological resource allocation as applied to hormesis. ${ }^{14,31,35,36}$ 

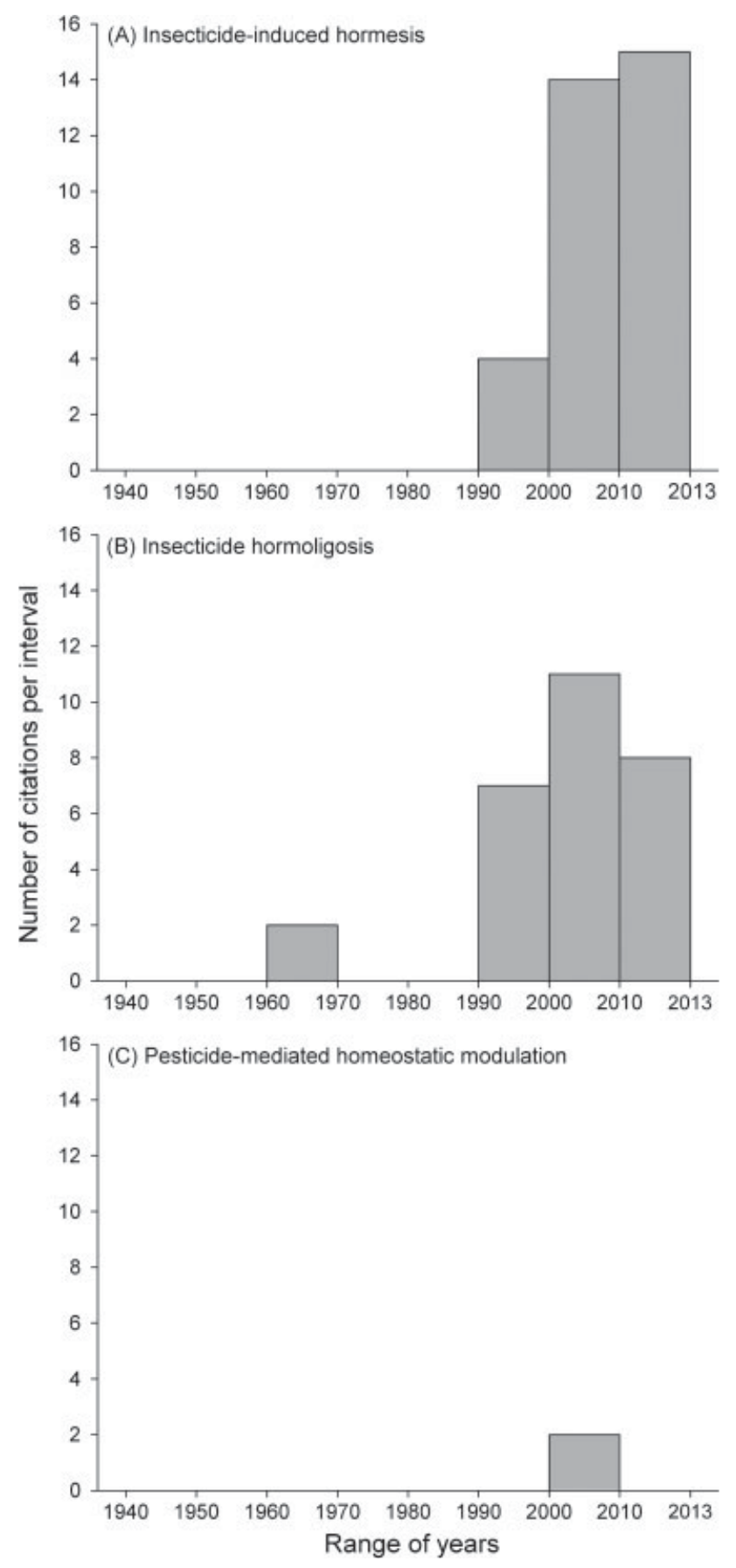

Figure 2. Citations of insecticide-induced hormesis (A), insecticide hormoligosis (B) and pesticide-mediated homeostatic regulation (C) registered over 10-year periods since the 1940s, when the concept of hormesis was initially proposed. Data were obtained from the Web of Science database (accessed 20 August 2013).

\subsection{Growth hormesis theory}

According to the growth theory, hormesis is a byproduct of homeostasis overcompensation. ${ }^{33,34}$ This idea has proven popular and is based on control systems and growth analysis. ${ }^{30,33}$ The assumption is that self-regulated processes (e.g. growth) and thus organism self-regulation require control systems with feedback responses. ${ }^{33,37}$ The control mechanisms that regulate growth counteract the perturbing or inhibitory effects of toxic agents. Hormesis is the alleged result of both transient and sustained overcorrection (or overcompensation) by the control system to low levels of inhibition by the toxic compound..$^{30,32-34,38}$ Although interesting, this hypothesis remains highly speculative and is mainly focused on growth as a life-history trait lacking a general mechanistic underpinning. ${ }^{14,25,26}$

\subsection{Principle of resource allocation}

The principle of resource allocation is the general basis of physiological energetic models that predict trade-offs in resource allocation among different physiological processes. ${ }^{31,35}$ Based on this principle and energy conservation laws, Jager et al ${ }^{14}$ suggest three broad categories of energy/mass management underlying hormesis: acquisition, medication and allocation. This view holds two fundamental assumptions: the functional link between physiology and fitness, and the existence of physiological costs associated with a toxic challenge. There is ample evidence to support these assumptions and this theory. ${ }^{35,39-45}$

Hormesis by acquisition reflects the increased performance of a stress-exposed individual and is explained by an unlimited increase in energy uptake from the environment, when such a resource is not limited. ${ }^{14}$ This increased energy uptake favors growth rate, and possibly maximizes size, which increase reproduction and population growth rate. This is exemplified by findings with insecticide-exposed spined soldier bugs and aphids. ${ }^{19,45}$ By contrast, hormesis by medication may occur when the toxicant is, or contains, an essential element in which the individual is deficient. This second view is more limited in scope. ${ }^{14}$

Hormesis by resource allocation is a more traditional and widely accepted notion in which the stress-exposed individual shifts the balance between potentially energy-conflicting physiological trade-offs, favoring one (e.g. reproduction) at the expense of another (e.g. longevity). ${ }^{14,31}$ Cadmium-exposed springtails and azadirachtin-exposed bean beetles (bruchids) both exhibited trade-off shifts, the first favoring longevity at the expense of growth and reproduction, and the latter favoring reproduction at the expense of longevity. ${ }^{46,47}$ In both situations, improved performance of one trait impairs the performance of the other. This may have either positive or negative fitness consequences for the individual depending on the traits involved and may exhibit transgenerational effects. ${ }^{14}$ In other cases, there may be no evidence of trade-offs within a generation of insects exposed to low doses of insecticide, but trade-offs across generations may occur, without any evidence of overall biological fitness being compromised. ${ }^{45}$ Similarly, evolution of insecticide resistance during exposure to low doses of insect growth regulators may induce evolutionary changes in metabolism or signaling that may mediate evolution of a longer life span without trade-offs with fecundity. ${ }^{48}$

The fitness consequences of hormesis likely depend on the underlying mechanism involved. The initial suspicion that hormesis in individual traits may not translate into improved fitness has been challenged of late by reports of enhanced population fitness due to insecticide-induced hormesis in insects and mites. $^{31,45,47,49,50}$ These recent findings suggest that insecticideinduced hormesis in arthropods may indeed be adaptive, as suspected and reported with other stress agents for other taxa, ${ }^{14,51-54}$ with potential consequences for arthropod pest management.

\section{HORMESIS IN ARTHROPODS}

Hormesis has been a subject of growing attention in the scientific literature with over 1700 published papers 
according to the Thomson Reuters database Web of Science (http://thomsonreuters.com/web-of-science/). However, only 82 $(4.82 \%)$ of those papers explore insecticide-induced hormesis (including hormoligosis) and only 50 (2.94\%) are devoted to insects and mites. Comprehensive lists of these studies were reported by Cohen, ${ }^{18}$ and more recently by Cutler. ${ }^{15}$ Here, we focus on trends and deficiencies in how the subject has been explored thus far in insect and mite studies. The past focus on lethality as the toxicological endpoint in insecticide studies with arthropods has likely been one of the barriers to recognizing both the occurrence and importance of hormesis in insects and mites, which is a sublethal phenomenon. In the past decade, the significance of the sublethal effects of insecticides on arthropods has become more accepted. ${ }^{55}$ This is important because exposure to low insecticide doses often occurs in the field due to insecticide degradation and the lower exposure of nontargeted arthropods (i.e. beneficials and nontargeted pests) that are usually less exposed or more tolerant to the compound than the target species.

\subsection{Hormesis in arthropod pest species}

Insecticide-induced hormesis in arthropod pest species has received only modest attention compared with hormesis studies in other disciplines (e.g. biomedical sciences). This is surprising because the phenomenon and its importance have been recognized since the 1950s. ${ }^{16,56}$ The fruit fly Drosophila melanogaster, house fly Muscadomestica, granary weevil Sitophilus granarius and house cricket Acheta domesticus were early subjects of study, particularly with exposure to sublethal doses of organochlorine insecticides. ${ }^{17,57-62}$ Insecticide-induced population stimulation in mites has been observed since the 1970s and has sparked concerns of insecticide-induced pest outbreaks among at least two mite species: the citrus red mite, Panonychus citri, and the two-spotted spider mite, Tetranychus urticae. ${ }^{18,63,64}$ More recently, pyrethroidinduced outbreaks of the southern red mite, Oligonychus ilicis, were examined. ${ }^{50}$ Thus, there is awareness of the hormesis phenomenon in insects and mites, but interest remains relatively modest, despite the increase in attention in the last decade. ${ }^{15}$

Insecticide-induced hormesis in arthropod pests has been studied for different biological traits, but its impact on reproductive traits and potential fitness consequences are most commonly reported. ${ }^{15,18}$ This provides support for the perception that insecticide-induced hormesis in arthropod pest species is adaptive, with potential consequences for pest management. ${ }^{14,15,18,50,56}$ More long-term laboratory and field studies are necessary to confirm this perception.

\subsection{Hormesis in natural enemies}

Interest in insecticide-induced hormesis in nontarget arthropods, particularly predators, started in the 1950s and 1960s with the lacewing Chrysopacalifornica, the ladybird beetle Coleomegillamaculata and the braconid parasitoid wasp Bracon hebetor. ${ }^{65-67}$ The big-eyed bug Geocoris spp. and the spined soldier bugs Podisus distinctus and Supputius cinceticeps were subsequently studied. ${ }^{19,68-71}$ Hormesis studies on natural enemies are more common with insect predators than parasitoids. We are aware of no study to date dealing with hormesis in entomopathogens.

There are few reports of insecticide-induced hormesis in natural enemies compared with arthropod pests, which may be due to the lack of preliminary evidence of occurrence. Although insecticideinduced pest population outbreaks have been reported for decades, no such observations with natural enemies appear in the literature. It is also likely that the long-standing emphasis and experimental bias toward the deleterious effects of insecticides on natural enemies have meant that researchers have remained naïve about potential stimulatory effects of chemicals on these taxa. Although natural enemies may be subject to hormesis, Morse ${ }^{20}$ suggests that there is less potential for hormesis in natural enemies in the field because they are generally more susceptible to insecticides compared with pest species, ${ }^{72}$ and because of the density-dependence of natural enemies on their prey or host species. Both may have an effect, but the overall lower susceptibility of natural enemies to current insecticides is disputable for more modern insecticides, ${ }^{73-76}$ and neither factor seems to play a direct role in the expression of hormesis in natural enemies.

\subsection{Plant-mediated hormesis?}

The possibility that insecticide applications may induce hormesis in arthropods indirectly via changes in plant physiology, is an intriguing concept. For example, imidacloprid-treated boxwoods (Buxus sempervirens L.) led to higher egg-laying activity by the boxwood mite Eurytetranychus buxi. ${ }^{74,75}$ Although no direct evidence of hormesis was provided in these studies (i.e. no concentration-response relationship was established nor were changes in plant physiology assessed), their findings, and the reported herbicide-induced performance improvement of plant species of economic value, ${ }^{22,77,78}$ suggest potential indirect impacts of insecticide hormesis in arthropods and their management, possibility that have been largely neglected.

\section{PEST MANAGEMENT, INSECTICIDE-INDUCED HORMESIS AND ECOLOGICAL BACKLASHES}

More than 50 years after the publication of Rachel Carson's Silent Spring, insecticides remain a major component of insect pest management and are still surrounded by controversy. ${ }^{79,80}$ However, changes in attitudes and policy over the use of pesticides against pest species have led to the development and use of insecticides with improved safety profiles towards human health and the environment. ${ }^{81,82}$

Insecticide applications leading to outbreaks of pest species were recognized as early as the early 1950s, following the onset of the large-scale use of organochlorine insecticides for arthropod pest control. ${ }^{56,83}$ Since then, these outbreaks have been relatively frequent, particularly for broad-spectrum insecticides. ${ }^{56,84,85}$ This form of ecological backlash was frequently dealt with by increasing insecticide use, which often leads to the 'pesticide treadmill' or 'pesticide syndrome'. ${ }^{84,86-88}$ Frequent or improper insecticide use is often associated with two ecological backlashes that can lead to pest control failures: insecticide resistance and pest resurgence or outbreaks, both of which have some common causes and are ecological consequences of insecticide applications. ${ }^{56,84,85,89,90}$ Insecticide-induced hormesis is potentially important in both cases.

\subsection{Insecticide-induced hormesis in insecticide-resistant populations}

Since the 1950s, the evolution of insecticide resistance in arthropod pests has been a major concern in agricultural and medical arthropod pest management. ${ }^{91-93}$ Insecticide-induced hormesis is potentially a complicating factor for arthropod pesticide 
resistance management because of the prevailing exposure of resistant insects to sublethal doses of insecticides in the field. The subject has been largely neglected and there are few studies that have explored this scenario.

Evidence of a hormesis-like stimulatory egg-laying response to the pyrethroid fenvalerate and the carbamate methomyl was detected in a Japanese strain of the diamondback moth, Plutellaxylostella, selected for resistance to each respective insecticide. ${ }^{94}$ However, the stimulatory effect was observed at a relatively high dose range exhibiting significant mortality $\left(L_{25}\right)$, and may have been an artifact of selection, which allowed the fitter individuals to survive and reproduce. Insecticide-induced hormesis was also reported in a strain of maize weevil, Sitophilus zeamais, resistant to the pyrethroid insecticide deltamethrin. ${ }^{49}$ Maize weevil fitness was significantly affected with increased population growth of the insecticide-resistant strain following sublethal insecticide exposure. ${ }^{49}$ This finding suggests a potential problem for managing insecticide-resistant populations because field doses of the insecticide may not control these insects and may actually boost their population growth (Fig. 3). There is preliminary evidence of higher insecticide-induced hormetic effect on the most resistant populations. ${ }^{95}$

Mechanistically, there are reasons to suspect that adaptive hormetic responses to low doses of insecticide might augment the development of resistance or increased tolerance to these compounds. Exposure of insects to sublethal doses of pesticides or plant allelochemicals can induce production of enzymes that are important in detoxification processes, ${ }^{96,97}$ and induction of esterases (hydrolases), which are important in pesticide metabolism, as observed during insecticide-induced hormesis in insects. ${ }^{98}$ If the propensity to express such detoxification enzymes during the hormetic response was a heritable epigenetic process without fitness costs, ${ }^{16,45,99}$ one could reasonably predict that the coupling of the hormetic response with detoxification gene induction could assist in insecticide resistance development. This hypothesis should be explored further.

\subsection{Insecticide-induced hormesis and arthropod pest outbreaks}

Pest resurgence and secondary pest outbreaks, although important and frequently reported, have received far less attention

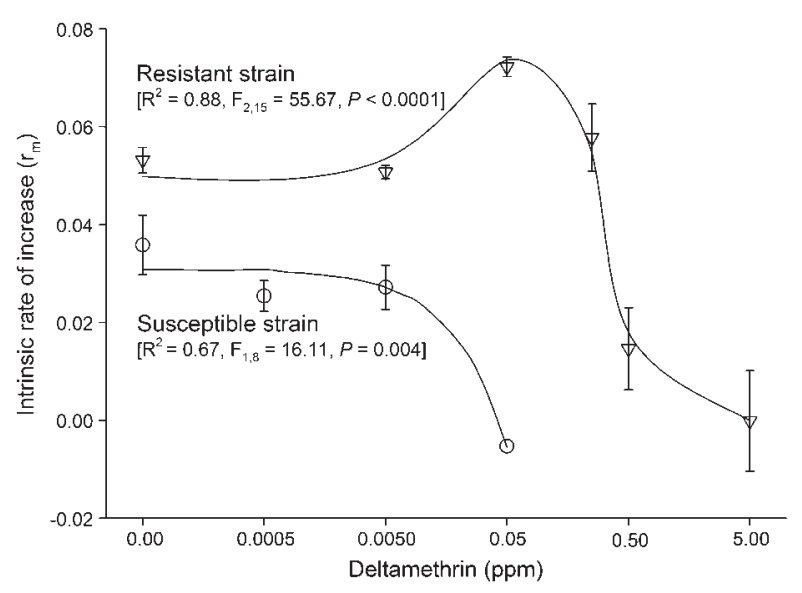

Figure 3. Intrinsic rate of population growth $\left(r_{\mathrm{m}} \pm \mathrm{SEM}\right)$ of a susceptible and a pyrethroid-resistant strain of the maize weevil (Sitophilus zeamais) exposed to sublethal doses of the pyrethroid insecticide deltamethrin $(n=3)$ (modified from Guedes et al, ${ }^{49}$ with added data from the susceptible strain). than insecticide resistance. Resurgence is an increase in abundance of the arthropod pest species targeted by the insecticide application to levels higher than those of the uncontrolled populations. ${ }^{56,85}$ By contrast, secondary pest outbreaks - also called pest replacement or type II resurgence - are an increase in the abundance of a nontargeted arthropod pest species after insecticide application. ${ }^{84.85}$ Both phenomena have common causes, including reduction in the number of natural enemies, increase of the pest population, and removal of competitors. ${ }^{56}$

The reduction of natural enemies is commonly thought to be the cause of the phenomenon, although it has seldom been tested, particularly at the population level. ${ }^{50,85}$ Insecticide-induced hormesis is a possible cause of outbreaks in some pest species. Evidence of insecticide applications directly stimulating arthropod populations outbreaks has been reported in mites, ${ }^{64}$ planthoppers, ${ }^{100}$ aphids ${ }^{101}$ and thrips. ${ }^{102}$ The southern red mite, Olygonychus ilicis, often exhibits outbreaks in coffee plantations after pyrethroid applications against the coffee leafminer, Leucopetera coffeella. Mite predators of the red mite are not compromised by the pyrethroid deltamethrin, which is more toxic to the red mite. ${ }^{50}$ In addition, deltamethrin did not lead to behavioral avoidance by the predatory mites but did induce hormesis in the red mite (Fig. 4). ${ }^{50}$

\section{BEYOND INSECTICIDE-INDUCED HORMESIS}

Hormesis is a general phenomenon and insecticide-induced hormesis may occur in arthropod pest species and their natural enemies. Pesticide-induced hormesis in crop plants may lead to yield increase, but it may also mediate arthropod pest outbreaks. $^{74,75,103,104}$ In addition, insecticide-induced hormesis may lead to arthropod pest outbreaks, and may impair the management of insecticide-resistant populations or augment resistance development in insects, illustrating the importance of this phenomenon to pest management.

The hormesis phenomenon is not, however, restricted to insecticides (or pesticides) as stress agents. ${ }^{9-13,15}$ Other environmental stress factors such as temperature, diet and UV

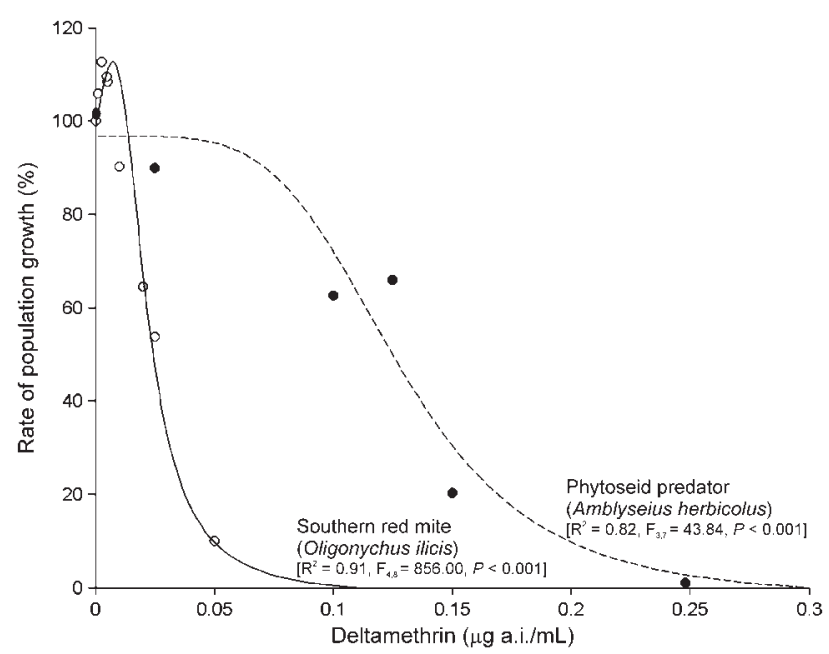

Figure 4. Observed concentration-response values and curve (Brain-Cousen model) based on the intrinsic rate of population growth $\left(r_{m}\right)$ of the southern red mite (Oligonychusilicis; o) and its phytoseid predator (Amblyseius herbicolus; $\bullet$ ) exposed to the pyrethroid insecticide deltamethrin (modified from Cordeiro et $a^{50}$ ). 
radiation, may also induce hormesis, which may have fitness implications relevant to evolutionary processes and with practical consequences. ${ }^{28,105-109}$ Combinations of these stressors may have important consequences for the concurrent expression of traits directly related to biological fitness, such as growth and resistance to pesticides, and hormesis may manifest in different ways depending on the combinations of stressors. ${ }^{103-109}$

Low (sublethal) levels of pesticide, heat or nutritional stress may also have potential uses in enhancing the productivity and/or efficacy of natural enemies, such as predators, parasitoids or insect pathogens. Utilization of the hormetic response might result in economic and performance benefits in culturing beneficial insects, mirroring the observed increases in productivity of plants exposed to low levels of stress. ${ }^{22}$ Thus, insecticide-induced hormesis is not only a potentially important phenomenon for the occurrence of arthropod pest resurgence and insecticide resistance development, but also for the development and improvement of techniques to reduce impacts of these pests.

\section{ACKNOWLEDGEMENTS}

The authors would like to thank the Editorial Board of Pest Management Science for the opportunity to prepare this review and A. Carrick for the guidance provided. The comments and suggestions provided by $\operatorname{Dr} \mathrm{S}$. Duke and three anonymous reviewers were greatly appreciated and acknowledged here. The financial support provided by the National Council of Scientific and Technological Development (CNPq), the CAPES Foundation (Brazilian Ministry of Education), the Minas Gerais State Foundation of Research Aid (FAPEMIG) and the Natural Sciences and Engineering Research Council of Canada is also acknowledged.

\section{REFERENCES}

1 Stumpf WE, The dose makes the medicine. Drug Discov Today 11:550-550 (2006).

2 Kendig EL, Le HH and Blecher SM, Defining hormesis: evaluation of a complex concentration response phenomenon. Int J Toxicol 29:235-246 (2010).

3 Jacobi J and Guterman N, Paracelsus: Selected Writings. Princeton University, Princeton, NJ (1995).

4 Schulz H, Uber Hefegifte. Pflug Arch Gesamte Physiol 42:517-541 (1888).

5 Hueppe F and Jordan EO, The Principles of Bacteriology. The Open Court, Chicago, IL (1899).

6 Calabrese EJ and Baldwin LA, The marginalization of hormesis. Hum Exp Toxicol 19:32-40 (2000).

7 Calabrese EJ, Hormesis: once marginalized, evidence now supports hormesis as the most fundamental dose response, in Hormesis: $A$ Revolution in Biology, Toxicology and Medicine, ed. by Mattson MP and Calabrese EJ. Springer, New York, pp. 15-56 (2010).

8 Southam CM and Ehrlich J, Effects of extract of Western redcedar heartwood on certain wood-decaying fungi in culture. Phytopathology 33:517-524 (1943).

9 Calabrese EJ and Baldwin LA, The dose determines the stimulation (and poison): development of a chemical hormesis database. Int J Toxicol 16:545-559 (1997).

10 Calabrese EJ and Baldwin LA, A quantitatively-based methodology for the evaluation of chemical hormesis. Hum Ecol Risk Assess 3:545-554 (1997).

11 Calabrese EJ and Baldwin LA, The frequency of U-shaped dose responses in the toxicological literature. Toxicol Sci 62:330-338 (2001).

12 Calabrese EJ and Baldwin LA, U-Shaped dose-response in biology, toxicology, and public health. Annu Rev Public Health 22:15-33 (2001).
13 Calabrese EJ and Blain R, The occurrence of hormetic dose responses in the toxicological literature, the hormesis database: an overview. Toxicol Appl Pharmacol 202:289-301 (2005).

14 Jager T, Barsi A and Ducrot V, Hormesis on life-history traits: is there such a thing as a free lunch? Ecotoxicology 22:263-270 (2013).

15 Cutler GC, Insects, insecticides and hormesis: evidence and considerations for study. Dose-Response 11:154-177 (2013).

16 Costantini D, Metcalfe NB and Monaghan P, Ecological processes in a hormetic framework. Ecol Lett 13:1435-1447 (2010).

17 Luckey TD, Insecticide hormoligosis. J Econ Entomol 61:7-12 (1968).

18 Cohen E, Pesticide-mediated homeostatic modulation in arthropods. Pestic Biochem Physiol 85:21-27 (2006).

19 Guedes RNC, Magalhães LC and Cosme LV, Stimulatory sublethal response of a generalist predator to permethrin: hormesis, hormoligosis, or homeostatic regulation? J Econ Entomol 102:170-176 (2009).

20 Morse JG, Agricultural implications of pesticide-induced hormesis of insects and mites. Hum Exp Toxicol 17:266-269 (1998).

21 Capinera JL, Hormoligosis, in Encyclopedia of Entomology, Vol. 2 (D-K), ed. by Capinera JL. Springer, Heidelberg, pp. 1851-1852 (2008).

22 Belz RG, Cedergreen N and Duke SO, Herbicide hormesis - can it be useful in crop production? Weed Res 51:321-332 (2011).

$23 \mathrm{Yu}$ Y, Shen G, Zhu H and Lu Y, Imidacloprid-induced hormesis on the fecundity and juvenile hormone levels of the green peach aphid Myzus persicae (Sulzer). Pestic Biochem Physiol 98:238-242 (2010).

24 Rozman KK and Doull J, Scientific foundation of hormesis. Part 2. Maturation, strengths, limitations and possible applications in toxicology, pharmacology, and epidemiology. Crit Rev Toxicol 33:451-462 (2003).

25 Thayer KA, Melnick R, Burns K, Davis D and Huff J, Fundamental flaws of hormesis for public health decisions. Environ Health Persp 113:1271-1276 (2005).

26 Mushak $\mathrm{P}$, Hormesis and its place in nonmonotonic dose-response relationships: some scientific reality checks. Environ Health Persp 115:500-506 (2007).

27 Rattan SIS, Hormesis in aging. Ageing Res Rev 7:63-78 (2008).

28 Mattson MP, Calabrese EJ, Hormesis: what it is and why it matters, in Hormesis: A Revolution in Biology, Toxicology and Medicine, ed. by Mattson MP and Calabrese EJ. Springer, New York, pp. 1-14 (2010).

29 Vaiserman AM, Hormesis, adaptive epigenetic reorganization, and implications for human health and longevity. Dose-Response 8:16-21 (2010).

30 Stebbing ARD, A theory of growth hormesis. BELLE News/ 6:1-11 (1997).

31 Forbes VE, Is hormesis an evolutionary expectation? Funct Ecol 14:12-24 (2000).

32 Stebbing ARD, Hormesis: Interpreting the $\beta$-curve using control theory. J App/ Toxicol 20:93-101 (2000).

33 Stebbing ARD, Maia hypothesis - growth control and toxicology. Hum Ecol Risk Assess 6:301-311 (2000).

34 Calabrese EJ, Evidence that hormesis represents an 'overcompensation' response to a disruption in homeostasis. Ecotoxicol Environ Safe 42:135-137 (1999).

35 Sibly RM and Calow P, Physiological Ecology of Animals - An Evolutionary Approach. Blackwell, Oxford (1986).

36 Weltje L, vom Saal FS and Oehlmann J, Reproductive stimulation by low doses of xenoestrogens contrasts with the view of hormesis as an adaptive response. Hum Exp Toxicol 24:431-437 (2005).

37 Milsum JH, Biological Control Systems Analysis. McGraw-Hill, New York (1966).

38 Calabrese EJ and Baldwin LA, Defining hormesis. Hum Exp Toxicol 21:91-97 (2002).

39 Calow P, Physiological costs of combating chemical toxicants: ecological implications. Comp Biochem Physiol C 100:3-6 (1991).

40 Daniel SH and Smith RH, Functional anatomy of the egg pore in Callosobruchus maculates: a trade-off between gas-exchange and protective functions? Physiol Entomol 19:30-38 (1994).

41 Calow $\mathrm{P}$ and Forbes VE, How do physiological responses to stress translate into ecological and evolutionary processes? Comp Biochem Physiol A 120:11 - 16 (1998).

42 Chown SL and Gaston K, Exploring links between physiology and ecology at macro-scales: the role of respiratory metabolism in insects. Biol Res 74:87-120 (1999). 
43 Coustau C, Chevillon $\mathrm{C}$ and ffrench-Constant RH, Resistance to xenobiotics and parasites: can we count the cost? Trends Ecol Evol 15:378-383 (2000).

44 Guedes RNC, Oliveira EE, Guedes NMP, Ribeiro B and Serrão JE, Cost and mitigation of insecticide resistance in the maize weevil. Physiol Entomol 31:30-38 (2006).

45 Ayyanath MM, Cutler GC, Scott-Dupree CD and Sibley PK, Transgenerational shifts in reproduction hormesis in green peach aphid exposed to low concentrations of imidacloprid. Plos One 8:e74532 (2013)

46 Jager T, Crommentuijn T, Van Gestel CAM and Kooijman SALM, Simultaneous modeling of multiple endpoints in life-cycle toxicity tests. Environ Sci Technol 38:2894-2900 (2004).

47 Vilca Mallqui KS, Vieira JL, Guedes RNC and Gontijo LM, Azadirachtinmediated shift in fecundity-longevity trade-off in the Mexican bean beetle Zabrotes subfasciatus. J Econ Entomol (in press).

48 Flatt Tand Kawecki TJ, Juvenile hormone as a regulator of the trade-off between reproduction and life span in Drosophila melanogaster. Evolution 61:1980-1991 (2007).

49 Guedes NMP, Tolledo J, Corrêa AS and Guedes RNC, Insecticideinduced hormesis in an insecticide-resistant strain of the maize weevil, Sitophilus zeamais. J Appl Entomol 134:142-148 (2010).

50 Cordeiro EMG, de Moura ILT, Fadini MAM and Guedes RNC, Beyond selectivity: are behavioral avoidance and hormesis likely causes of pyrethroid-induced outbreaks of the southern red mite Olygonychus ilicis? Chemosphere 93:1111-1116 (2013).

51 Parsons PA, Radiation hormesis: an evolutionary expectation and the evidence. Appl Rad Isotopes 41:857-860 (1990).

52 Parsons PA, The hormetic zone: an ecological and evolutionary perspective based upon habitat characteristics and fitness selection. Q Rev Biol 76:459-467 (2001).

53 Stark M, Hormesis, adaptation, and the sandpile model. Crit Rev Toxicol 38:641-644 (2008).

54 Mattson MP, The fundamental role of hormesis in evolution, in Hormesis: A Revolution in Biology, Toxicology and Medicine, ed. by Mattson MP and Calabrese EJ. Springer, New York, pp. 57-68 (2010).

55 Desneux N, Decourtye A and Delpuech J-M, The sublethal effects of pesticides on beneficial arthropods. Annu Rev Entomol 52:81-106 (2007).

56 Ripper WE, Effect of pesticides on balance of arthropod populations. Annu Rev Entomol 1:403-438 (1956).

57 Knutson $H$, Modifications in fecundity and lifespan of Drosophila melanogaster Meigen following sublethal exposure to an insecticide. Ann Entomol Soc Am 48:35-39 (1955).

58 Afifi SED and Knutson $\mathrm{H}$, Reproductive potential, longevity, and weight of house flies which survived one insecticidal treatment. $J$ Econ Entomol 49:310-313 (1966).

59 Kilpatrick JW, Schoof JH, Fly production in treated ad untreated privies. Public Health Rep 71:787-796 (1956).

60 Ouye MT and Knutson H, Reproductive potential, longevity, and weight of house flies following treatments of larvae with malathion. J Econ Entomol 50:490-493 (1957).

61 Hunter PE, Cutkomp LK and Kolkaila AM, Reproduction in DDT- and diazinon-treated house flies. J Econ Entomol 11:579-582 (1958).

62 Kuenen DJ, Influence of sublethal doses of DDT upon the multiplication rate of Sitophilus granaries (Coleoptera: Curculionidae). Entomol Exp App/ 1:147-152 (1958).

63 Saini RS and Cutkomp LK, The effects of DDT and sublethal doses of dicofol on reproduction of the two-spotted spider mite. J Econ Entomol 59:249-253 (1966).

64 Dittrich V, Streibert P and Bathe PA, An old case reopened: mite stimulation by insecticide residues. Environ Entomol 3:534-540 (1974).

65 Fleschner CA and Scriven GT, Effect of soil-type and DDT on ovipositional response of Chrysopacalifornica (Coq.). J Econ Entomol 50:221-222 (1957).

66 Atallah YH and Newson LL, Ecological and nutritional studies on Coleomegilla maculate De Geer (Coleoptera: Coccinelidae). III. The effects of DDT, toxaphene, and endrin on the reproductive and survival potentials. J Econ Entomol 59:1181-1187 (1966).

67 Grosch DS and Vacovic LR, Chlorinated hydrocarbon insecticides are not mutagenic in Braconhebetor tests. J Econ Entomol 60:1177-1179 (1967).
68 Farlow RA and Pitre HN, Bioactivity of the post emergent herbicides acifluorfen and bentazon on Geocoris punctipes (Say) (Hemiptera: Lygaeidae). J Econ Entomol 76:200-203 (1983).

69 Yokoyama VY and Pritchard J, Effect of pesticides on mortality, fecundity and egg viability of Geocorispallens (Hemiptera: Lygaedae). J Econ Entomol 77:876-879 (1984).

70 Magalhães LC, Guedes RNC, Oliveira EE and Tuelher ES, Development and reproduction of the predator Podisusdistinctus (Stal) (Heteroptera: Pentatomidae). Neotrop Entomo/ 31:445-448 (2002).

71 Zanuncio TV, Serrão JE, Zanuncio JC and Guedes RNC, Permethrininduced hormesis on the predator Supputius cincticeps (Stal, 1860) (Heteroptera: Pentomidae). Crop Prot 22:941 - 947 (2003).

72 Croft BA, Arthropod Biological Control Agents and Pesticides. Wiley, New York (1990).

73 Gil LI and Gill SS, Insect Control: Biological and Synthetic Agents. Academic Press, London (2010).

74 Szczepaniec A and Raupp MJ, Effects of imidacloprid on spider mite (Acari: Tetranychidae) abundance and associated injury to boxwoods. Arboric Urban For 38:37-39 (2012).

75 Szczepaniec A and Raupp MJ, Direct and indirect effects of imidacloprid on fecundity and abundance of Eutetranychus buxi (Acari: Tetranychidae) on boxwoods. Exp Appl Acarol 59:307-318 (2013).

76 Casida JE and Durkin KA, Neuroactive insecticides: targets, selectivity, resistance, and secondary effects. Annu Rev Entomol 58:99-117 (2013).

77 Duke SO, Cedergreen N, Velini D and Belz RG, Hormesis: is it an important factor in herbicide use and allelopathy? Outlooks Pest Manag 17:29-33 (2006)

78 Cedergreen N, Streibig JC, Kudsk P, Mathiassen SK and Duke SO, The occurrence of hormesis in plants and algae. Dose-Response 5:150-162 (2007).

79 Cooper J and Dobson $\mathrm{H}$, The benefits of pesticides to mankind and the environment. Crop Prot 26:1337-1348 (2007).

80 Edwards-Jones G, Do benefits accrue to 'pest control' or 'pesticides'?: a comment on Cooper and Dobson. Crop Prot 27:965-967 (2008).

81 Matsumura F, Contemporary issues on pesticide safety. J Pestic Sci 29:299-303 (2004).

82 Matthews GA, Attitudes and behaviours regarding use of crop protection products - a survey of more than 8500 smallholders in 26 countries. Crop Prot 27:834-846 (2007).

83 Pickett $A D, A$ critique on insect chemical control methods. Can Entomol 81:67-76 (1949).

84 Metcalf RL, Changing role of insecticides in crop protection. Annu Rev Entomol 25:219-256 (1980).

85 Hardin MR, Benrey B, Colt M, Lamp W, Roderick GK and Barbosa P, Arthropod pest resurgence: an overview of potential mechanisms. Crop Prot 14:3-18 (1995).

86 Doutt RL, Smith RF, The pesticide syndrome - diagnosis and suggested prophylaxis, in Biological Control, ed. by Huffaker CB. Plenum, New York, pp. 3-15 (1971).

87 Pedigo LP, Entomology and Pest Management. MacMillam, New York (1989).

88 DeBach P, Rosen D, Biological Control by Natural Enemies. Cambridge University Press, New York (1991).

89 Georghiou GP, The evolution of resistance to pesticides. Annu Rev Entomol 3:133-168 (1972).

90 Battsten LB, Holyoke Jr CW, Leeper JR and Raffa KF, Insecticide resistance: challenge to pest management and basic research. Science 231:1255-1260 (1986).

91 Whalon ME, Mota-Sanchez D, Hollingworth RM, Global Pesticide Resistance in Arthropods. CABI, Wallingford, UK (2008).

92 Hemingway J, Vontas J, Poupardin R, Raman J, Lines J, Schwabe C et al, Country-level operational implementations of the Global Plan for Insecticide Resistance Management. Proc Natl Acad SciUSA 110:9397-9402 (2013).

93 Oakeshott JG, Farnsworth CA, East PD, Scott C, Ha Y, Wu Y, et al, How many genetic options for evolving insecticide resistance in heliothine and spodopteran pests? Pest Manag Sci 69:889-896 (2013).

94 Sota N, Motoyama N, Fujisaki K and Nakasuji F, Possible amplification of insecticide hormoligosis from resistance in the diamondback moth, Plutellaxylostella (Lepidoptera: Yponomeutidae). Appl Entomol Zool 33:435-440 (1998).

95 Veloso RVS, Proteômica Diferencial em Populações de Sitophilus zeamais (Motschulsky, Coleoptera: Curculionidae) 
mediante expressão do fenômeno hormese. DS Dissertation, Univ. Fed. Viçosa, Brazil (2012).

96 Terriere LC, Induction of detoxification enzymes in insects. Annu Rev Entomol 29:71-88 (1984).

$97 \mathrm{Yu}$ SJ, Host plant induction of microsomal monooxygenases in relation to organophosphate activation in fall armyworm larvae. FI Entomol 69:579-587 (1984).

98 Mukherjee SN, Rawal SK, Ghumare SS and Sharma RN, Hormetic concentrations of azadirachtin and isoesterase profiles in Tribolium castaneum (Herbst) (Coleoptera: Tenebrionidae). Experientia 49:557-560 (1993).

99 Vaiserman AM, Hormesis and epigenetics: is there a link? Ageing Res Rev 10:413-421 (2011).

100 Chelliah S and Heinrichs EA. 1980. Factors affecting insecticideinduced resurgence of the brown planthopper, Nilaparvata lugens, on rice. Environ Entomol 9:773-777.

101 Lowery DT and Sears MK. 1986. Stimulation of reproduction of the green peach aphid (Homoptera: Aphididae) by azinphosmethyl applied to potato. J Econ Entomol 79:1530-1533.

102 Morse JG and Zareh N. 1991. Pesticide-induced hormoligosis of citrus thrips (Thysanoptera: Thripidae) fecundity. J Econ Entomol 84:1169-1174.
103 Belz RG, Cedergreen $\mathrm{N}$ and Sørensen $\mathrm{H}$, Hormesis in mixtures - can it be predicted? Sci Total Environ 404:77-87 (2008).

104 Szczepaniec A, Creary SF, Laskowski KL, Nyrop JP and Raupp MJ, Neonicotinoid insecticide imidacloprid causes outbreaks of spider mites on elm trees in urban landscapes. PLOS ONE 6, e20018 (2011).

105 Paperiello CJ, Risk assessment and risk management implications of hormesis. J Appl Toxicol 20:147-148 (2000).

106 Feinendegen LE, Evidence for beneficial low level radiation effects and radiation hormesis. Br J Radiol 78:3-7 (2005).

107 Sarup P and Loeschcke V, Life extension and the position of the hormetic zone depends on sex and genetic background in Drosophila melanogaster. Biogerontology 12:109-117 (2011).

108 López-Martínez G and Hahn DA, Short-term anoxic conditioning hormesis boosts antioxidant defenses, lowers oxidative damage following irraditation and enhances male sexual performance in the Caribbean fruit fly, Anastrephasuspense. J Exp Biol 215: 2150-2161 (2012).

109 Piiroinen S, Lyytinen A and Lindström L, Stress for invasion success? Temperature stress of preceding generations modifies the response to insecticide stress in an invasive pest insect. Evol Appl 6:313-323 (2013). 